\title{
Effect of loose abrasive mixed electrolyte on the aspect ratio of blind holes drilled in soda-lime glass by ECDM process
}

\author{
Vijaya Vani Vemula and Sanjay Kumar Chak \\ Division of Manufacturing Process and Automation Engineering, Netaji Subhas Institute of Technology, New Delhi-110078, India
}

Received: 6 May 2020 / Accepted: 18 October 2020

\begin{abstract}
Electro-Chemical Discharge Machining (ECDM) process has the potential to machine various features and 3D surfaces on glass. However, machining of high aspect ratio micro holes is a challenging problem in ECDM process. In ECDM process, the machining rate mainly depends on the availability of the electrolyte at the electrode tip. Machining accuracy like taper, entry and exit diameter of the hole at high depths is rigorously affected due to lack of electrolyte at the machining zone resulting in more taperness. Low surface qualities (i.e. more over cut and tapered micro holes) are few limitations of the process. To enhance the machining capabilities a novel approach of PMECDM has been conducted. Present study is mainly focused on behavior of abrasive particles while machining soda lime glass, also studied effect of process parameters on the responses such as machining depth, outer diameter and aspect ratio. Also, the study led to analyze the effect of thermal properties of abrasives on machining performance of ECDM process. The maximum machined depth achieved was $2.31 \mathrm{~mm}$ in $5 \mathrm{~min}$, and tremendous reduction of outer diameter from $1237.37 \mu \mathrm{m}$ to $712.8 \mu \mathrm{m}$. Response surface methodology has been used to plan the experiments and ANOVA has been used to analyze the impact of each process parameters on machined depth and outer diameter of the micro holes.
\end{abstract}

Keywords: Powder Mixed Electro Chemical Discharge Machine (PMECDM) / soda lime glass / aspect ratio / abrasives / machining depth

\section{Introduction}

In a state-of-the art of manufacturing technology, glass is the most widely used material in micro-electro mechanical devices (MEMS), due to its good bondage to silicon, and its similar coefficient of expansion. Optical transparency, high stiffness, florescence, good thermal and chemical resistance, bio-compatibility, high dielectric strength $[1,2]$ are some of the special features of glass which increase its demand in the field of micro electro mechanical systems (MEMS), micro fluidic devices like solid oxide fuel cell for portable electronic device, micro reactors and micro pumps. In the modern era, the evolution of Micro and Nano applications of glass, machining of micro holes with high aspect ratio, and high accuracy with repeatability is challenging task. Hard and brittle nature of glass possesses challenges for machining with high accuracy and efficiency, especially in micro machining applications like MEMS, Micro reactors and micro pumps [3]. The main limiting factor for the growing use of glass in these applications is its

\footnotetext{
* e-mail: sanjaykchak@yahoo.com
}

limiting structuring property. Several machining techniques for the structuring of glass and difficulties associated with them have been reported in the literature. Unlike conventional machining techniques such as turning, drilling, milling, etc., the generation of symmetrical features and complex shapes is a highly challenging task because of its brittleness. In the chemical etching process, due to the amorphous nature of the glass, it attacks equally in all directions. Hence structures with curved side walls with low aspect ratios are created by isotropic wet etching $[4,5]$, whereas in case of dry etching of glass, structural depth is limited due to slow etch rate [6]. In thermal process, such as laser micro machining process, applications of high thermal energy micro cracks are developed and difficult to produce good surface finish [7]. In mechanical machining methods, such as ultrasonic machining, high tool wear and debris accumulation is the main limitations. In abrasive jet machining the material is removed by using highspeed jet particles, which is able to machine complex structures. However, this process is hindered due to poor surface finish and limited to larger components [8,9]. Micro system applications, such as in micro electro mechanical systems (MEMS), precise machining of glass is needed. 
Table 1. Aspect ratio achieved by different researchers in ECDM process.

\begin{tabular}{llllll}
\hline S.No & Material & Diameter $(\mu \mathrm{m})$ & Depth $(\mu \mathrm{m})$ & Aspect ratio & Reference \\
\hline 1 & Glass & 340 & 450 & 1.32 & {$[19]$} \\
2 & Glass & 328 & 550 & 1.67 & {$[20]$} \\
3 & Quartz & 468.7 & $1 \mathrm{~mm}$ & & {$[21]$} \\
4 & Optical glass & $2.5 \mathrm{~mm}$ & $5.02 \mathrm{~mm}$ & 2.008 & {$[22]$} \\
5 & Soda lime & 860 & 400 & 0.46 & {$[23]$} \\
6 & Quartz & 643.41 & 1348 & 2.1 & {$[24]$} \\
\hline
\end{tabular}

\section{Literature of powder mixed EDM, ECM and ECDM}

Chow et al. [10] conducted the EDM process by adding SiC and aluminum powders into kerosene for the micro slit machining of titanium alloy. They reported that mixed $\mathrm{SiC}$ and aluminum powder to the kerosene enhanced the gap distance, resulting in higher debris removal rate and material removal depth. Sahu et al. [11] introduced $\mathrm{SiC}$ powder in water as dielectric for micro slit operation. They conclude that addition of $\mathrm{SiC}$ powder increases the electrical conductivity and enlarge the interelectrode gap, resulting in improved surface finish of the micro slits.

Ajay Batish et al. [12] mixed graphite, silicon and tungsten powder particles in to the dielectric while machining AISI 1045 steel. Powder concentration and composition plays a vital role on the overcut. An increase in the powder concentration will result directly in increase in overcut, this could be due to powder particles getting entrapped in the machining gap resulting in increase in discharge length, which results in prolonged overcut. Kannan et al. [13] had reported an attempt of mixing nano copper particles into the electrolyte while machining Inconel 718 in the Powder mixed ECM process. The adaptive neurofuzzy inference system was used to predict the models, and concluded that roughness value was decreased.

Balwinder singh et al. [14] had mixed graphite, $\mathrm{Al}_{2} \mathrm{O}_{3}$ and $\mathrm{SiC}$ in ECDM process and reported that abrasive addition in electrolyte reduces the surface roughness. Yang et al. [15] introduced $\mathrm{SiC}$ abrasives into electrolyte in WECDM process. Also, reported that abrasives addition tremendously reduced the slit expansion by increasing critical voltage.

In literature, researchers have reported various stumbling blocks in ECDM process as a limitation on machining depth due to lack of electrolyte, thermally damaged machined surface and low aspect ratios [16,17]. Achieving good surface quality is a challenging task in ECDM process. Attention is still needed in the area of machining micro holes with high aspect ratio on electrically non-conducting materials viz. glass. Gupta et al. [18] studied the effect of pulse duration on aspect ratio and reported that, aspect ratio increases with increase in duty factor, however, duty factor above 0.75 shows the declining trend, maximum aspect ratio achieved was 0.16 . In addition, the below table (Tab. 1) gives the information of maximum aspect ratio achieved by researchers on glass and quartz.
From the available literature it is evident that several researches have conducted experiments by using different powder mix and different techniques to improve the aspect ratio but performance improvement of the process still needs to be researched. Also, extensive study is still needed in the area of powder mixed ECDM process especially how the powder characteristics influence the machining performance. There is a need to improve the accuracy of micro hole machining like over cut quality and achieving maximum depth with less taperness in ECDM process. Thus, this study was undertaken with a specific objective to improve the machining performance of ECDM process by adding different abrasives and their effect on overcut and aspect ratio.

This paper deals with the effects of different process parameters like applied voltage (V), electrolyte concentration (wt\%) on machined depth, entry diameter and aspect ratio during the drilling blind holes in soda lime glass. Response Surface Methodology has been used to plan the experiments and ANOVA (Analysis of Varience) has been used to analyze the responses.

\section{Experimentation}

The inbuilt experimental setup for the current study is shown in Figure 1. The setup consists of the following subassemblies:

- Electrolyte tank with work piece holder, tool electrode, a counter electrode, and a submersible pump

- DC power supply unit.

- Vertical column with electrode feed mechanism.

An electrolyte tank of size $250 \times 140 \times 100 \mathrm{~mm}$ is made up of Perspex sheet of $8 \mathrm{~mm}$ thickness. It contains a counter electrode (anode), tool electrode (cathode), work holder and a submersible pump to circulate the electrolyte inside the tank. The system consists of a DC power supply, and an electrode feeding system to maintain a constant gap with work piece (soda lime glass) placed on a work holder which is immersed in the electrolyte.

The distance between the tool electrode tip and the work piece is of the order of $30 \mu \mathrm{m}$, which is measured with the help of a feeler gauge. The immersion depth of the cathode inside the electrolyte is maintained at a distance of $2 \mathrm{~mm}$, dial gauge of $0.01 \mathrm{~mm}$ accuracy is used to measure the immersion depth. Machining efficiency depends on the feeding mechanism of the tool electrode [25]. Different 


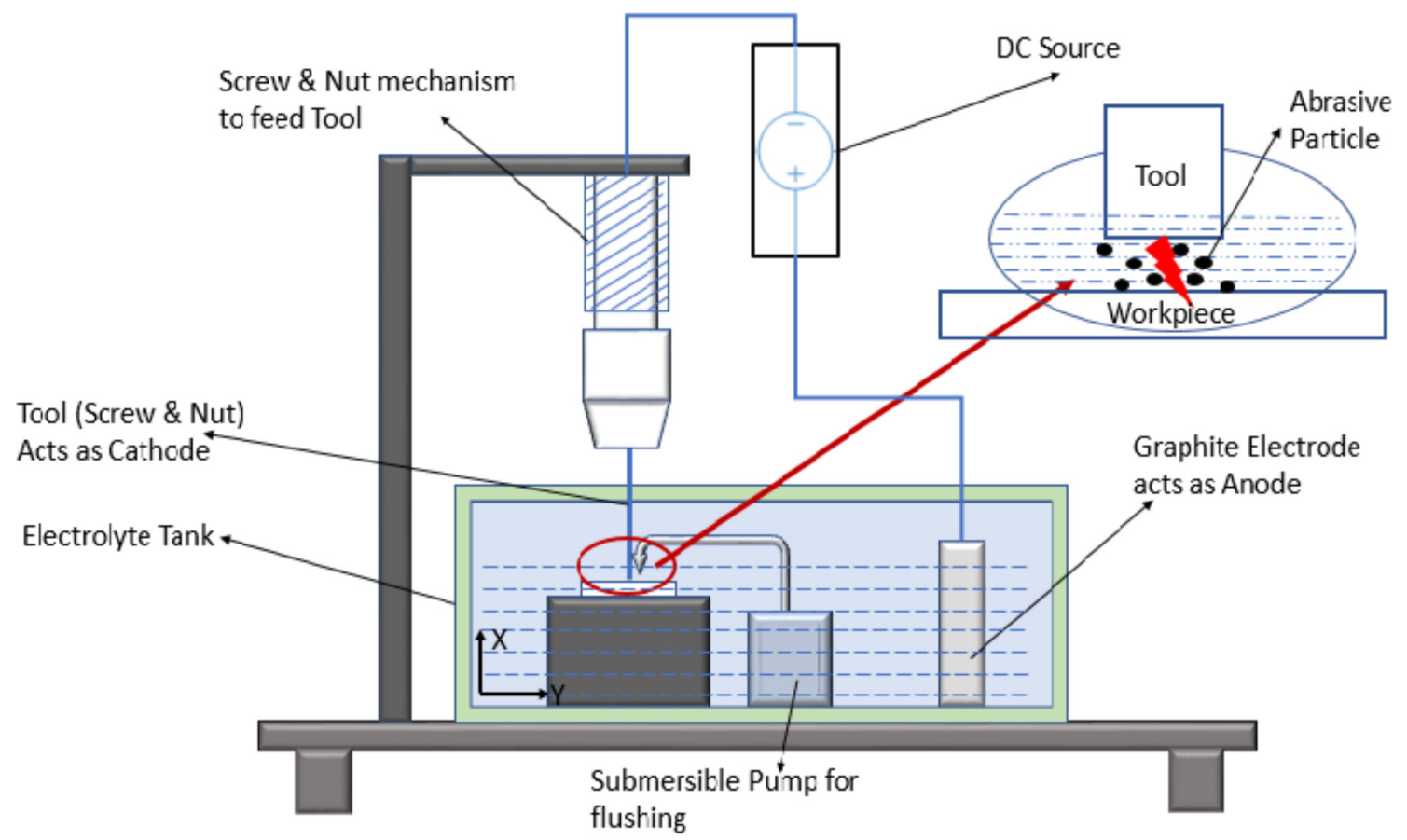

Fig. 1. Electro Chemical Discharge machining setup with power supply.

feeding mechanisms are used by the researchers, constant drilling speed (no monitoring of drilling speed); constant gap machining, closed-loop machining (no suitable control signal known so far); counter resistant feeding [26], spring feed mechanism [21] and gravity feed mechanism [27]. Among all, the gravity feeding mechanism was most frequently used, but certain drawbacks are reported in gravity feeding, such as tool breakage and drilling depth beyond $480 \mu \mathrm{m}$, micro cracks are developed at the bottom face of the glass which could be due to the loading of the contact force [28]. Also, gravity feeding ensures the physical contact between tool and the work piece results in lessening the bubbles evolved at the bottom face of the cathode. This limits the penetration depth by minimizing the number of sparks generation at the bottom face of the cathode.

The tool feeding method used in the present study is a screw-nut mechanism that feeds the cathode to a specified depth. The pitch of the screw was $0.8 \mathrm{~mm}$ and the circumference of the shaft was divided in to 20 equal divisions so that one division gives $0.04 \mathrm{~mm}(0.8 / 20)$ transverse motion of the cathode. The minimum feed which could be achieved was $0.04 \mathrm{~mm} / \mathrm{min}$. The distance between the cathode and anode is kept $30 \mathrm{~mm}$ in all experiments. In the present study a mixture of $\mathrm{KOH}$ and distilled water is used as an electrolyte at different concentrations, along with a DC pulse power supply range between 0 and $120 \mathrm{~V}$ with 5 A current. When DC power is applied across the electrodes, electrolysis occurs, resulting in liberation of hydrogen bubbles at the cathode and oxygen bubbles at the anode as shown in the reactions given below.

Reactions at the cathode (Tungsten Carbide)

Plating of metal ions:

$M^{+}+e^{-} \rightarrow M$, where $\mathrm{M}$ represents anode material,
Evolution of hydrogen gas:

$$
2 \mathrm{H}_{2} \mathrm{O}+2 e^{-} \rightarrow 2(\mathrm{OH})^{-}+\mathrm{H}_{2} \uparrow \quad \text { (in } \mathrm{KOH} \text { solution.) }
$$

Reactions at auxiliary (Graphite) electrode

Dissolution of metal ions:

$$
M \rightarrow M^{+}+e^{-}
$$

Evolution of oxygen gas:

$$
4(\mathrm{OH})^{-} \rightarrow 2 \mathrm{H}_{2} \mathrm{O}+\mathrm{O}_{2} \uparrow+4 e^{-}
$$

As the voltage further increased and reached the critical voltage, the density and the mean radius of the hydrogen gas bubbles increases and their coalescence forms a gaseous layer around the electrode, which acts as a dielectric that isolates the tool electrode from the work piece, and the ionization of the gas inside the layer causes the electric discharges. These discharges are focused beam of electrons which impinges with a high velocity and acceleration on the work piece surface and raises the temperature greater than the melting temperature of the glass causing the material removal by thermal melting while some of its amount is removed by chemical action.

The following chemical etching reaction is as follows

$$
\mathrm{SiO}_{2}+\mathrm{KOH} \rightarrow \mathrm{K}_{2} \mathrm{SiO}_{3}+\mathrm{H}_{2} \mathrm{O}
$$

Silica present in glass reacts with $\mathrm{KOH}$ and forms potassium silicate as a precipitate. The potassium ion $\left(\mathrm{K}^{+}\right)$, and hydroxide ion $(\mathrm{OH})$ in the electrolyte reacts with the glass. The Si-O-Si bond present in the glass is broken and changed into $-\mathrm{Si}-\mathrm{O}-\mathrm{K}-$ bond.

\section{Results and discussions}

In the present study, influencing process parameters such as voltage (31-43 V), electrolyte concentration (15-35\%), 
Table 2. Interaction effect of parameters.

\begin{tabular}{lllllll}
\hline Run order & Voltage & $\begin{array}{l}\text { \% Elect. } \\
\text { conc. }\end{array}$ & $\begin{array}{l}\text { Over cut }(\mathrm{mm}) \\
\text { with } \mathrm{SiC}\end{array}$ & $\begin{array}{l}\text { Machined depth(mm) } \\
\text { with } \mathrm{Al}_{2} \mathrm{O}_{3}\end{array}$ & $\begin{array}{l}\text { Aspect ratio } \\
\text { with } \mathrm{Al}_{2} \mathrm{O}_{3}\end{array}$ & $\begin{array}{l}\text { Aspect ratio } \\
\text { with } \mathrm{SiC}\end{array}$ \\
\hline 1 & 34 & 30 & 0.388 & 1.4 & 6.79 & 3.29 \\
2 & 37 & 15 & 0.341 & 0.9 & 2.03 & 2.34 \\
3 & 37 & 25 & 0.233 & 1.6 & 4.42 & 5.19 \\
4 & 40 & 30 & 0.209 & 1.8 & 2.82 & 6.69 \\
5 & 37 & 25 & 0.321 & 1.7 & 5.31 & 4.14 \\
6 & 37 & 25 & 0.255 & 2.0 & 6.36 & 4.705 \\
7 & 43 & 25 & 0.604 & 2.3 & 3.441 & 2.48 \\
8 & 37 & 25 & 0.305 & 1.9 & 4.65 & 4.26 \\
9 & 37 & 35 & 0.212 & 1.75 & 2.76 & 4.24 \\
10 & 40 & 20 & 0.285 & 1.53 & 2.82 & 4.58 \\
11 & 37 & 25 & 0.286 & 1.39 & 3.25 & 4.18 \\
12 & 34 & 20 & 0.301 & 1.2 & 3.25 \\
13 & 31 & 25 & 0.209 & 1.48 & & 6.12 \\
\hline
\end{tabular}

pulse off and on time (1 ms and $3 \mathrm{~ms}$ ), and their effects on entry diameter, depth and aspect ratio of the machined blind hole on soda lime glass with and without adding the loose abrasive particles in electrolyte have been calculated and shown in Table 2.

\subsection{Effect of process parameters on outer diameter}

Adding abrasives into electrolyte does not promote the chemical etching, but it promotes the effects on the ECDM mechanism in two aspects: First, the addition of abrasives maintains the gap which helps in the availability of electrolyte at the electrode tip as the machining proceeds.

Controlling the machining gap in ECDM process is a challenging task. If the machining gap increases, most of the energy liberated is transferred into the electrolyte due to convection, resulting sufficient heat energy is not available for melting of glass. Controlling the machining gap to some extent is achieved by adding the abrasives into electrolyte, also optimizes the gas film quality as shown in Figure 2. In the abrasive ECDM process, the machining gap is the order of same size of the abrasive particles. Hence abrasive mixed electrolyte helps in maintaining consistent gap as compared to conventional ECDM process. Also, this helps to provide sufficient electrolyte at the bottom face of the electrode, thus resulting discharge takes place more at the bottom as compared to side walls of the electrode and more accurate holes can be generated.

Second, these hard abrasives disrupt the bubble accumulation and reduce the discharge energy which results in craters with smaller entry diameters shown in Figure 3a. Outer diameter (OD) of the machined holes is shown in panels b-d of Figure 3b-d with conventional electrolyte, $\mathrm{SiC}$ and $\mathrm{Al}_{2} \mathrm{O}_{3}$ having values $1237.37 \mu \mathrm{m}$, $712.8 \mu \mathrm{m}$, and $821 \mu \mathrm{m}$, respectively. From the results it is observed that abrasive addition has significant effect on OD, abrasives helped locally to push away the melted glass

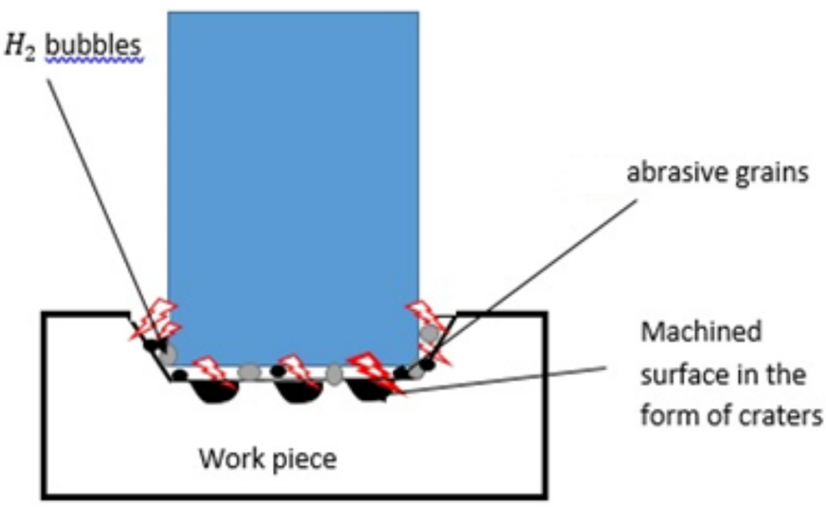

Fig. 2. Mechanism of ECDM with abrasive present in electrolyte.

along with the debris, allowing more electrolyte flow into the machining zone causing greater discharge at the bottom surface of the electrode than its sides, resulting in reduction of entry diameter. Addition of $\mathrm{SiC}$ in electrolyte has generated craters with smaller diameters and more consistent circular shapes (Fig. 3a), this may be due to high thermal conductivity of $\mathrm{SiC}$ particles compared to $\mathrm{Al}_{2} \mathrm{O}_{3}$. Higher thermal conductivity of abrasives provides less heat energy at the machining zone while more heat energy is transmitted by the abrasives from the machining zone, as a result craters of smaller diameters are obtained by $\mathrm{SiC}$ as shown in Figure 3d.

Figure 4a shows the effect of applied voltage on the outer diameter and also shows the comparative study with and without the addition of abrasives into the electrolyte. From Figure 4a it is clear that increase in the voltage increases the entry diameter due to liberation of more hydrogen bubbles that results in intensifying the discharge energy.

Through an experimental parametric study, it was found that the outer diameter increases and then decreases 


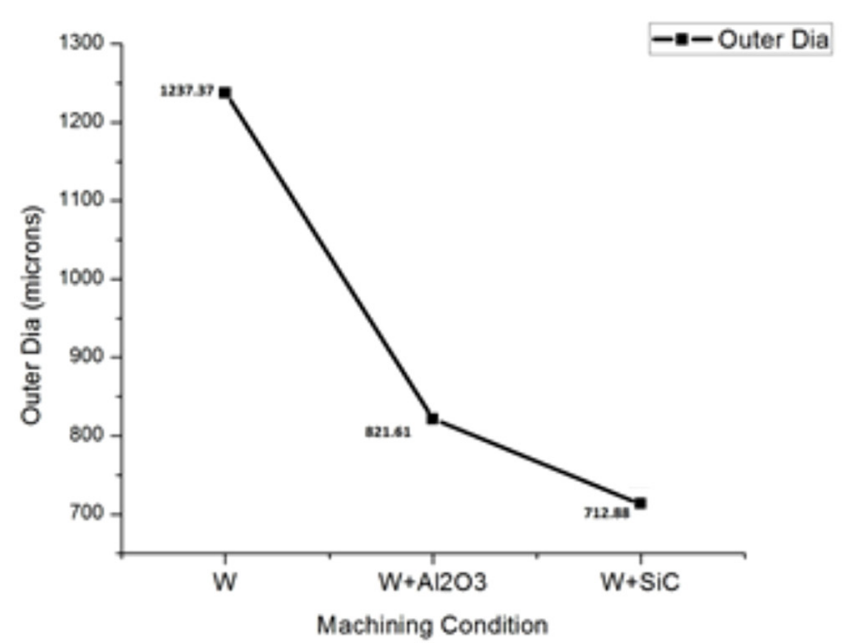

(a)

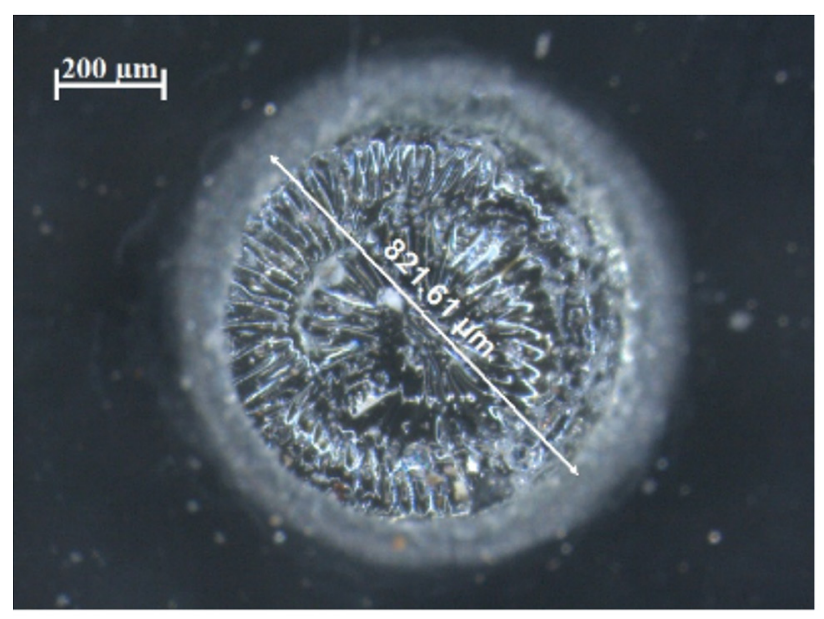

(c)

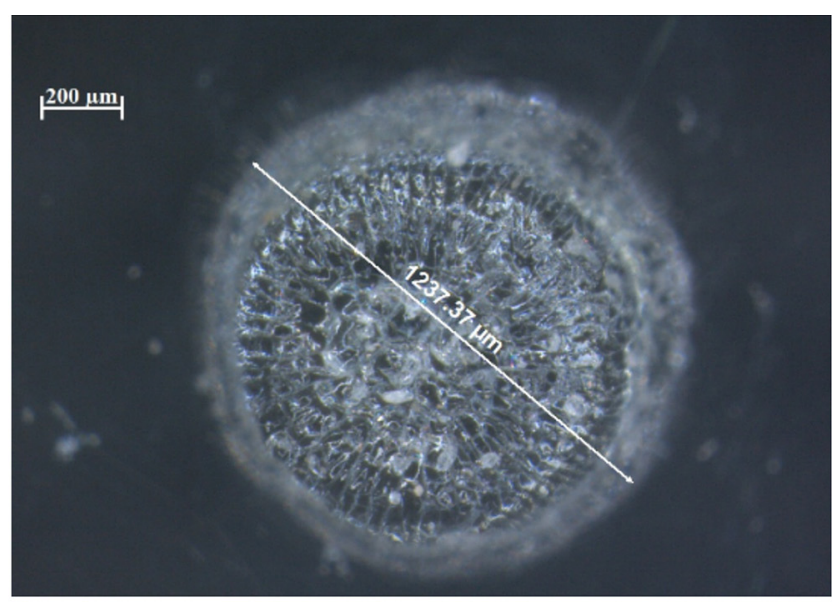

(b)

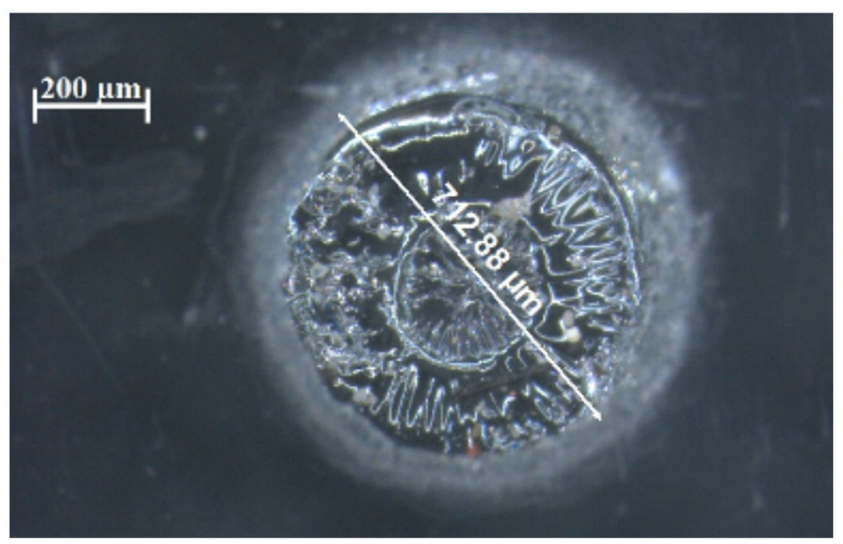

(d)

Fig. 3. (a) The influence of different machining conditions on outer diameter. (b) Outer diameter of the machined hole with Conventional ECDM process electrolyte. (c) Outer diameter of the machined hole with $\mathrm{Al}_{2} \mathrm{O}_{3}$ abrasives mixed ECDM process. (d) Outer diameter of the machined hole with $\mathrm{SiC}$ abrasives mixed ECDM process.
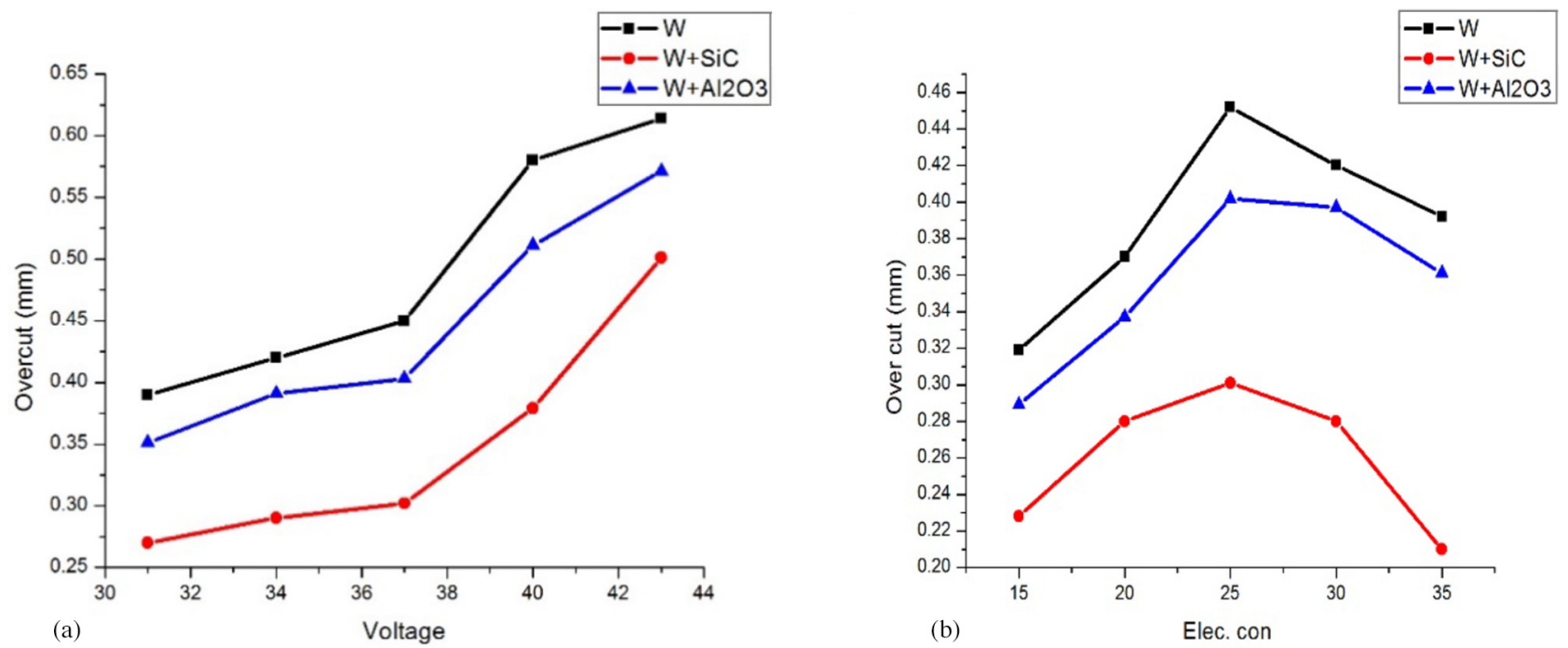

$(\%)$

Fig. 4. (a) Effect of voltage on the outer diameter. (b) Effect of electrolyte conc. on the outer diameter. 
Table 3. ANOVA for outer diameter.

\begin{tabular}{|c|c|c|c|c|c|c|}
\hline Source & Sum of squares & $\mathrm{df}$ & Mean square & $F$-value & $P$-value & \\
\hline A-Voltage & 0.0346 & 1 & 0.0346 & 28.02 & 0.0011 & \\
\hline $\mathrm{AB}$ & 0.0000 & 1 & 0.0000 & 0.0203 & 0.8908 & \\
\hline $\mathrm{A}^{2}$ & 0.0063 & 1 & 0.0063 & 5.08 & 0.0588 & \\
\hline Lack of Fit & 0.0021 & 3 & 0.0007 & 0.4359 & 0.7395 & Not significant \\
\hline Pure Error & 0.0065 & 4 & 0.0016 & & & \\
\hline Cor Total & 0.1286 & 12 & & & & \\
\hline
\end{tabular}

with increase in concentration as shown in Figure $4 \mathrm{~b}$, this could be due to maximum electrical conductivity at 25 wt. \% concentration of $\mathrm{KOH}$. With increase in electrical conductivity, the current drawn capacity increases and as a result more liberation of hydrogen gas bubbles at the cathode. Thus, sparks generated in the gas layer reaches to a maximum value at $25 \mathrm{wt} . \%$ electrolyte concentration and then shows the decreasing trend with further increase in concentration.

The analysis has been done using Central Composite Rotatable Design (CCRD) for the response, and presented ANOVA in Table 3.

In the above model $F$-value of 19.44 implies the model is significant, otherwise only $0.06 \%$ chance could be of noise. $P$-values less than 0.0500 indicate model terms are significant. In this case $\mathrm{A}$ is a significant model term. Values greater than 0.1000 indicate the model terms are not significant. The Lack of Fit $F$-value of 0.44 implies the lack of Fit is not significant relative to the pure error. There is a $73.95 \%$ chance that a Lack of Fit $F$-value this large could occur due to noise.

The Predicted $\mathrm{R}^{2}$ of 0.7577 is in reasonable agreement with the Adjusted $\mathrm{R}^{2}$ of 0.8848 i.e., the difference is less than 0.2. Also signal to noise ratio greater than 4 is desirable. In the present study ratio of 16.199 indicates an adequate signal. This model can be used to navigate the design space.

\subsection{Regression equation}

Outer Diameter $=+1.93306-0.107983 *$ Voltage $0.013174 *$ Electrolyte $+0.000167 *$ Voltage $*$ Electrolyte $+0.001838 *$ Voltage $^{2}+0.000097 *$ Electrolyte $^{2}$

The above equation is the predicted regression model for outer diameter, which confirms the $93.28 \%$ confidence level from Table 4.

\subsection{Effect of process parameters on machined depth}

In the electro-chemical discharge machining process, the material removal is mainly due to discharge erosion and chemical etching process. However, the discharge intensity
Table 4. Fit statistics.

\begin{tabular}{llll}
\hline Std. deviation & 0.0351 & $\mathrm{R}^{2}$ & 0.9328 \\
\hline Mean & 0.3572 & Adjusted $\mathrm{R}^{2}$ & 0.8848 \\
C.V\% & 9.84 & Predicted R & 0.7577 \\
& & Adeq Precision & 16.1986 \\
\hline
\end{tabular}

plays a major role in material removal and accuracy of machining which mainly depends on the availability of electrolyte at the electrode tip, due to which the spark intensity drastically varies the machined depth. The intensity of the spark varies inversely as the machining depth increases, this could be due to the bubbles that accumulate near the micro hole entrance than at the bottom due to lack of electrolyte flow at the bottom of the electrode tip.

Figure $5 \mathrm{a}$ shows the effect of voltage on the machined depth of the blind holes, revealing that as the voltage increases, spark intensity increases which decreases the strength of the glass; abrasives present in the electrolyte help in removing the debris by allowing the fresh electrolyte into the machining zone, resulting in increased machined depth. Availability of electrolyte around the tool tip is the essential requirement for a drilling process to improve the accuracy.

Table 5 represents the electrical conductivity of $\mathrm{KOH}$ electrolyte at different concentrations. At lower concentrations (15 wt.\% KOH) machining is very low, due to low conductivity of electrolyte (i.e. $280 \mathrm{mmho} / \mathrm{cm}$ ) gas bubbles generate with lower numbers and combine to form an unstable gas layer around the electrode with lower intensity resulting in reduction of the total number of discharges in gas film, which leads to instability of the sparks shown in Figure 5b. As the concentration increases from $15 \%$ to $25 \%$, the conductivity of electrolyte reaches to a maximum value (i.e. at $25 \%$ concentration conductivity is $345 \mathrm{mmho} / \mathrm{cm}$ ), which enhances the current signals and intensifies the liberation of $\mathrm{OH}$ radicals, resulting in higher discharge energy. However, further increase in concentration of electrolyte after $25 \%$, the conductivity of the 


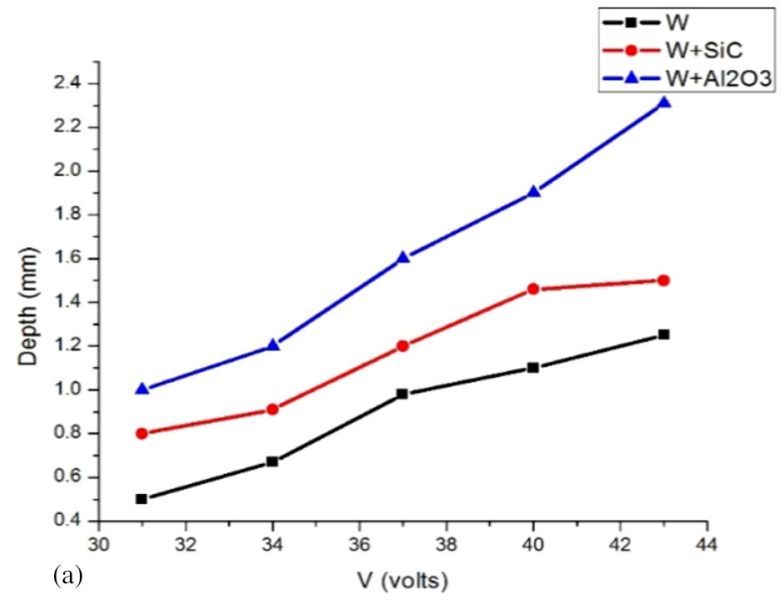

Fig. 5. (a) Effect of voltage on machined depth. (b) Effect of electrolyte concentration on depth.
Table 5. Values of electrical conductivity of $\mathrm{KOH}$ at different concentrations.

\begin{tabular}{ll}
\hline $\begin{array}{l}\text { Electrolyte } \\
\text { conc. }(\%)\end{array}$ & $\begin{array}{l}\text { Electrical conductivity } \\
(\mathrm{mmho} / \mathrm{cm})\end{array}$ \\
\hline 15 & 280 \\
20 & 310 \\
25 & 345 \\
30 & 323 \\
35 & 308 \\
\hline
\end{tabular}

electrolyte decreases due to ionic interactions and saturation of the electrolyte reveals the decreasing trend from $25 \%$ to $35 \%$ of $\mathrm{KOH}$ electrolyte.

ECDM with abrasive mixed electrolyte resulted in higher machined depth, the reason attributed can be abrasives helps in greater availability of electrolyte by maintaining a consistent gap between the electrode and work piece. Addition of $\mathrm{Al}_{2} \mathrm{O}_{3}$ shows a significant effect on machined depth, this could be due to low thermal conductivity of $\mathrm{Al}_{2} \mathrm{O}_{3}$ compared to $\mathrm{SiC}$ resulting in higher heat availability at the machining zone. Figure 6 shows the maximum depth achieved with $\mathrm{Al}_{2} \mathrm{O}_{3}$ was $2.31 \mathrm{~mm}$ in 5 min.

\subsubsection{ANOVA for machined depth}

The analysis has been done using the CCRD for the response depth, and presented the ANOVA in the following Table 6 .

In the above ANOVA Table 6, the Model $F$-value of 23.10 implies the model is significant. There is only a $0.03 \%$ chance that an $F$-value this large could occur due to noise. $P$-values less than 0.0500 indicate model terms are significant. In this case $\mathrm{A}, \mathrm{B}, \mathrm{B}^{2}$ are significant model terms. Values greater than 0.1000 indicate the model terms
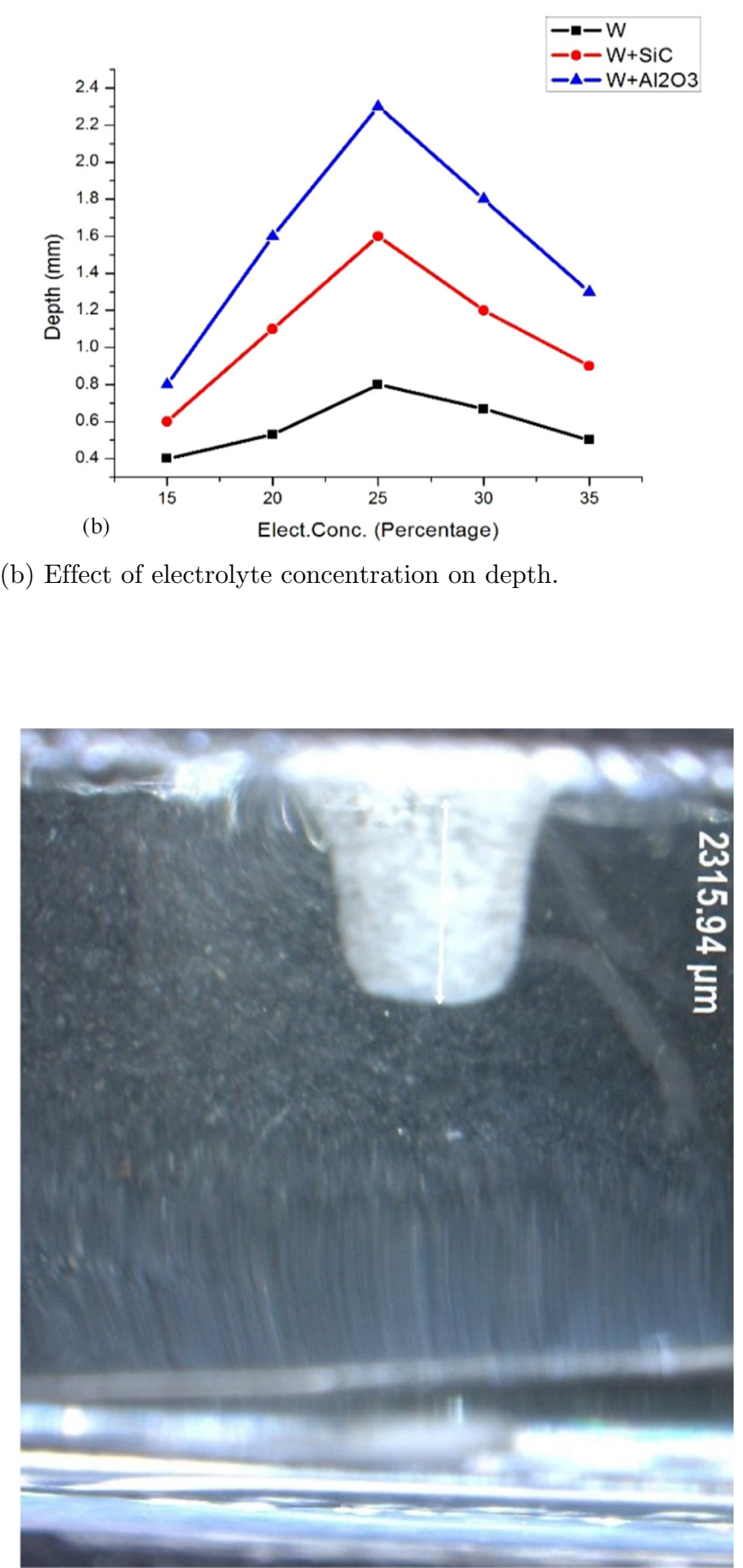

Fig. 6. Side view of micro hole machined at $37 \mathrm{~V}, 25 \%$ with $\mathrm{Al}_{2} \mathrm{O}_{3}$.

are not significant. If there are many insignificant model terms (not counting those required to support hierarchy), model reduction may improve the model.

The Lack of fit $F$-value of 0.47 implies the lack of fit is not significant relative to the pure error. There is a $71.97 \%$ chance that a lack of fit $F$-value this large could occur due to noise. Non-significant lack of fit is good.

From Table 7, the predicted $\mathrm{R}^{2}$ of 0.8253 is in reasonable agreement with the Adjusted $\mathrm{R}^{2}$ of 0.9020 i.e., the difference is less than 0.2 . Adeq. precision measures 
Table 6. Analysis of variance for machined depth.

\begin{tabular}{llllll}
\hline Source & Sum of squares & df & Mean square & F-Value & $P$-Value \\
\hline Model & 2.05 & 5 & 0.4105 & 23.10 & 0.0003 \\
A-Voltage & 0.9387 & 1 & 0.9387 & 52.82 & 0.0002 \\
B-Electrolyte & 0.1808 & 1 & 0.1808 & 10.17 & 0.0153 \\
AB & 0.0056 & 1 & 0.0056 & 0.3165 & 0.5913 \\
$\mathrm{~A}^{2}$ & 0.0337 & 1 & 0.0337 & 1.90 & 0.2108 \\
$\mathrm{~B}^{2}$ & 0.3630 & 1 & 0.3630 & 20.43 & 0.0027 \\
Residual & 0.1244 & 7 & 0.0178 & & 0.7197 \\
Lack of Fit & 0.0324 & 3 & 0.0108 & & Not significant \\
Pure Error & 0.0920 & 4 & 0.0230 & & \\
Cor Total & 2.18 & 12 & & & \\
\hline
\end{tabular}

Table 7. Fit statistics.

\begin{tabular}{llll}
\hline Std. dev & 0.1333 & $\mathrm{R}^{2}$ & 0.9429 \\
\hline Mean & 1.63 & ${\text { Adjusted } \mathrm{R}^{2}}^{2}$ & 0.9020 \\
C.V\% & 8.16 & Predicted $\mathrm{R}^{2}$ & 0.8253 \\
& & Adeq precision & 14.9065 \\
\hline
\end{tabular}

the signal to noise ratio. A ratio greater than 4 is desirable. The ratio of 14.906 indicates an adequate signal. This model can be used to navigate the design space.

\subsection{Final regression equation in terms of actual factors}

Depth $=-14.48314+0.490421^{*}$ Voltage $+0.376724 *$ Electrolyte- $0.002500 *$ Voltage*Electrolyte- $0.004262 *$ Voltage $^{2}$ $-0.005034^{*}$ Electrolyte $^{2}$

The above equation is the predicted regression model for depth which confirms the $94.29 \%$ confidence level from Table 7 .

\subsection{Effect of process parameters on aspect ratio}

Aspect ratio (AR) is mainly influenced by various factors such as lack of availability of electrolyte at the machining zone, accumulation of the machined debris, insufficient wetting of the electrode tip as the machining depth progress, and more spark intensity at the entrance than exit, which are the contributing factors for the low aspect ratio of the drilled holes. The results entitled in earlier sections were analyzed to study the effect of abrasive mixed electrolyte on aspect ratio.

The aspect ratio is calculated by the ratio of machined depth at entry diameter of the machined blind holes. The addition of $\mathrm{Al}_{2} \mathrm{O}_{3}$ has improved the aspect ratio. At lower voltages the spark intensity is low, when the voltage increases the discharge takes place not only at the end of the tool but also at the sides, which increases the outer diameter, so the aspect ratio is more at the low voltages, as shown in Figure 7. Note that how the aspect ratio changes

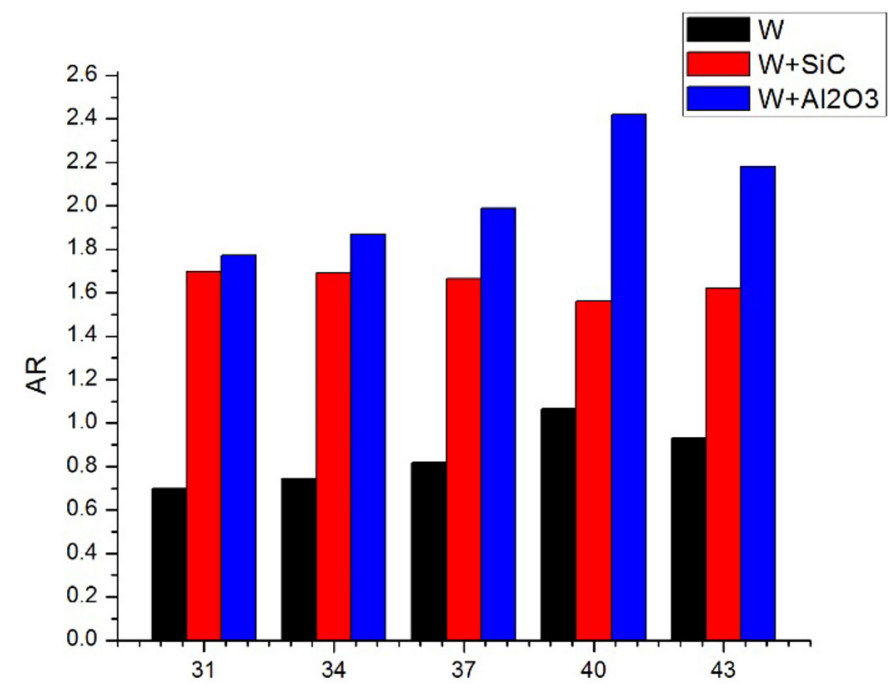

Fig. 7. Voltage vs. AR with different abrasives at $25 \%$ by $\mathrm{Al}_{2} \mathrm{O}_{3}$ in electrolyte.

significantly with different voltages and also it is a function of electrolyte motion state. Aspect ratio is a function of measured depth of machining to entry diameter. As the voltage increases the thermal intensity of the sparks increases causing the material removal from the work piece. Aspect ratio is high when the electrolyte concentration increases with lower voltages, and at higher voltages with low electrolyte concentrations, similar observations were found in [29], at lower concentrations of electrolyte liberation of hydrogen bubbles were reduced, spark energy in the gas film was low which reduces the entry diameter of the hole, enabling higher aspect ratio.

By adding the abrasives into electrolyte spark intensity was reduced, even though critical voltage was increased but some amount of energy was utilized for isolating the bubble layer, less spark energy was released for machining resulting [15], reduction entry diameter of the hole subsequently improving the aspect ratio and machining quality. 


\section{Conclusions}

In order to improve the aspect ratio and to promote the machining precision in electrochemical discharge micro drilled blind holes on soda lime glass, this study was performed by adding loose abrasives in the electrolyte. Based on the experiments, results are summarized as follows.

- Compared with conventional ECDM, the abrasive mixed ECDM process, machining performance as regards machined depth, surface morphology i.e, reduction in overcut is much superior.

- Abrasives present in electrolyte play a major role in improving the performance characteristics of the blind micro holes drilled on soda lime glass in terms of outer diameter. By adding abrasives outer diameter was remarkably reduced from $1237.37 \mu \mathrm{m}$ to $712.8 \mu \mathrm{m}$. Also, the maximum machining depth achieved $2.31 \mathrm{~mm}$ in 5 min by adding $\mathrm{Al}_{2} \mathrm{O}_{3}$ abrasives in the electrolyte.

- As the machining depth proceeds, lack of electrolyte circulation causes the accumulation of debris in the machining area, and the hydrogen bubbles trapped in the hole will hardly escape. They then tend to join with each other in order to reduce the interface energy between one another that causes the discharges on the side faces of the electrode than at the bottom.

- Abrasives help to maintain consistent spark gap, allowing the more electrolyte to flow. Improving the availability of the electrolyte on the machining zone helps in reducing the spark intensity at the entrance resulting in reducing the outer diameter and by increasing the inner diameter of the holes, ultimately resulting in reduced taperness of the holes; so the aspect ratio is improved further. The maximum aspect ratio was achieved by adding $\mathrm{SiC}$ is 6.69 .

\section{References}

1. A. Daridon, V. Fascio, J. Lichtenberg et al., Fresenius, J. Anal. Chem. 371 (2001) 261-269

2. D. Petersen, K. Mogensen, H. Klank, Glass micromachining. Microsystem engineering of Lab-on-a-Chip devices (Wiley-VCH Verlag GmbH \& Co. KGaA, Weinheim, 2004)

3. R. Tölke et al., Processing of Foturan ${ }^{\circledR}$ glass ceramic substrates for micro-solid oxide fuel cells, J. Eur. Ceram. Soc. 32 (2012) 3229-3238

4. C. Thierry, E. Peter, S. Göran, Deep wet etching of borosilicate glass using an anodically bonded silicon substrate as mask, J. Micromech. Microeng. 8 (1998) 84

5. Y. Mourzina, A. Steffen, A. Offenhäusser, The evaporated metal masks for chemical glass etching for BioMEMS. Vol. 11. (2005), 135-140

6. X. Li, T. Abe, M. Esashi, Deep reactive ion etching of Pyrex glass using SF6 plasma, Sens. Actuat. A 87 (2001) 139-145

7. S. Nikumb, Q. Chen, C. Li, H. Reshef, H. Y. Zheng, H. Qiu, D. Low, Precision glass machining, drilling, and profile cutting by short pulse lasers, Thin Solid Films 477 (2005) 216-221
8. P. J. Slikkerveer, P. Bouten, High quality mechanical etching of brittle materials by powder blasting. Sens. Actuat. A Phys. 85 (2000) 296-303

9. J.A. Plaza et al., Definition of high aspect ratio glass columns, Sens. Actuat. A Phys. 105 (2003) 305-310

10. H.-M. Chow et al., Study of added powder in kerosene for the micro-slit machining of titanium alloy using electrodischarge machining, J. Mater. Process. Technol. 101 (2000) 95-103

11. S.K. Sahu et al., Effect of using $\mathrm{SiC}$ powder-added dielectric media during electro-discharge machining of Inconel 718 superalloys, J. Braz. Soc. Mech. Sci. Eng. 40 (2018) 330

12. A. Batish, A. Bhattacharya, N. Kumar, Powder Mixed Dielectric: An Approach for Improved Process Performance in EDM, Part. Sci. Technol. 33 (2015) 150-158

13. S. Kumar, K. Pr, NANO POWDER MIXED ECM OF INCONEL 718 USING ANFIS AND RSM. 2020

14. R.O.V. Balwinder Singh, Vikas Sheel, Machining of Borosilicate Glass with ECDM using different abrasives. Int. Res. J. Eng. Technol. 04 (2017) 2533-2541

15. C.T. Yang et al., Improving machining performance of wire electrochemical discharge machining by adding SiC abrasive to electrolyte, Int. J. Mach. Tools Manuf. 46 (2006) 2044-2050

16. P. Maillard et al., Geometrical characterization of microholes drilled in glass by gravity-feed with spark assisted chemical engraving (SACE), J. Micromech. Microeng. 17 (2007) 1343

17. Z. Zhi-Ping et al., 3D microstructuring of Pyrex glass using the electrochemical discharge machining process, J. Micromech. Microeng. 17 (2007) 960

18. P.K. Gupta, A. Dvivedi, P. Kumar, Effect of Pulse Duration on Quality Characteristics of Blind Hole Drilled in Glass by ECDM, Mater. Manuf. Process. 31 (2016) 1740-1748

19. C. Chih-Ping et al., Magnetic field-assisted electrochemical discharge machining, J. Micromech. Microeng. 20 (2010) 075019

20. H. Min-Seop, M. Byung-Kwon, L. Sang Jo, Geometric improvement of electrochemical discharge micro-drilling using an ultrasonic-vibrated electrolyte, J. Micromech. Microeng. 19 (2009) 065004

21. H. Chao-Ching, D.-S.W.C. Jia-Chang, Flow-jet-assisted electrochemical discharge machining for quartz glass based on machine vision, Measurement 128 (2018) 71-83

22. F. Mehrabi et al., Application of electrolyte injection to the electro-chemical discharge machining (ECDM) on the optical glass, J. Materials Process. Technol. 255 (2018) $665-672$

23. Y. Xu et al., Experimental investigation of magnetohydrodynamic effect in electrochemical discharge machining, Int. J. Mech. Sci. 142-143 (2018) 86-96

24. V.K. Jain, Fabrication of Microchannels in Ceramics (Quartz) Using Electrochemical Spark Micromachining (ECSMM), J. Adv. Manuf. Syst. 13 (2014) 5-16

25. R. Wuthrich, V. Fascio, Machining of non-conductive materials using electrochemical discharge phenomenonan overview, Int. J. Mach. Tools Manuf. 45 (2005) 1095-1108 
26. Y. Xu et al., Investigation of micro-drilling using electrochemical discharge machining with counter resistant feeding, J. Mater. Process. Technol. 257 (2018) 141-147

27. M. Jalali, P. Maillard, R. Wüthrich, Toward a better understanding of glass gravity-feed micro-hole drilling with electrochemical discharges, J. Micromech. Microeng. 19 (2009) 045001
28. Z. Zhi-Ping et al., The tool geometrical shape and pulse-off time of pulse voltage effects in a Pyrex glass electrochemical discharge microdrilling process, J. Micromech. Microeng. 17 (2007) 265

29. S.K. Jui, A.B. Kamaraj, M.M. Sundaram, High aspect ratio micromachining of glass by electrochemical discharge machining (ECDM), J. Manuf. Process. 15 (2013) 460-466

Cite this article as: Vijaya Vani Vemula, Sanjay Kumar Chak, Effect of loose abrasive mixed electrolyte on the aspect ratio of blind holes drilled in Soda-lime Glass by ECDM process, Manufacturing Rev. 7, 37 (2020) 